\title{
CAMBRIDGE
}

\section{Great Titles from Cambridge!}

Second Edition

\section{Computational}

Electromagnetics for RF and Microwave Engineering

David B. Davidson

\$89.00: Hb: 978-0-521-51891-8: $530 \mathrm{pp}$
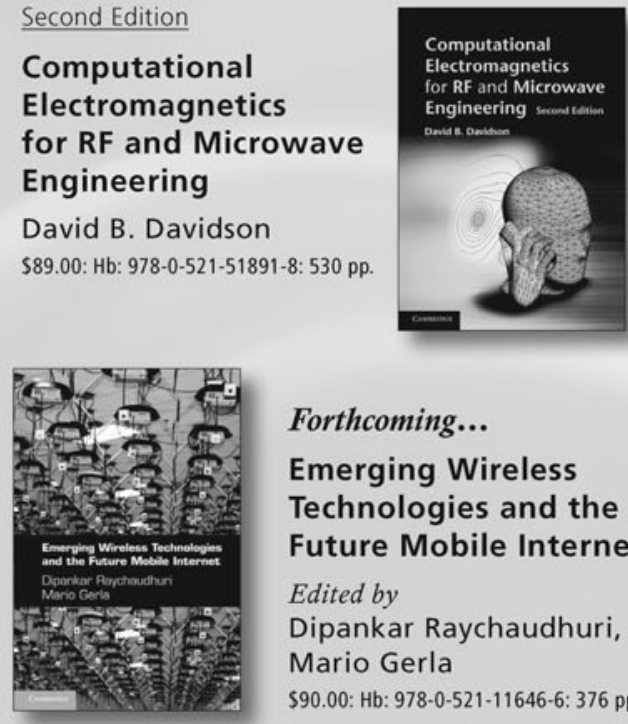

Forthcoming...

Emerging Wireless

Technologies and the Future Mobile Internet Edited by

Dipankar Raychaudhuri, Mario Gerla

\$90.00: Hb: 978-0-521-11646-6: $376 \mathrm{pp}$.

Forthcoming...

Numerical

Electromagnetics The FDTD Method

Umran S. Inan, Robert A. Marshall \$95.00: Hb: 978-0-521-19069-5: 384 pp.

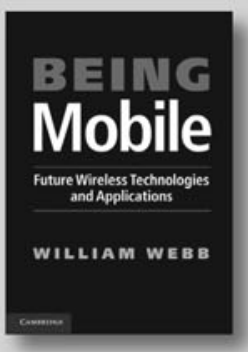

\section{Being Mobile}

Future Wireless

Technologies

and Applications

William Webb

S75.00: Hb: 978-1-107-00053-7: 230 pp.

\section{Advanced RF MEMS}

Edited by

Stepan Lucyszyn

The Cambridge RF and

Microwave Engineering Series

\$99.00: Hb: 978-0-521-89771-6: 440 pp.

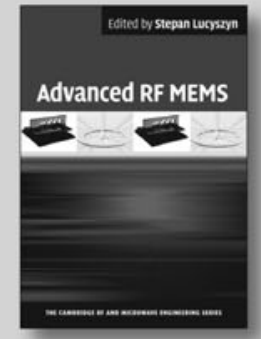

Essentials of

Short-Range

Wireless

Nick Hunn

The Cambridge Wireless

Essentials Series

S59.00: Hb: 978-0-521-76069-0: $344 \mathrm{pp}$
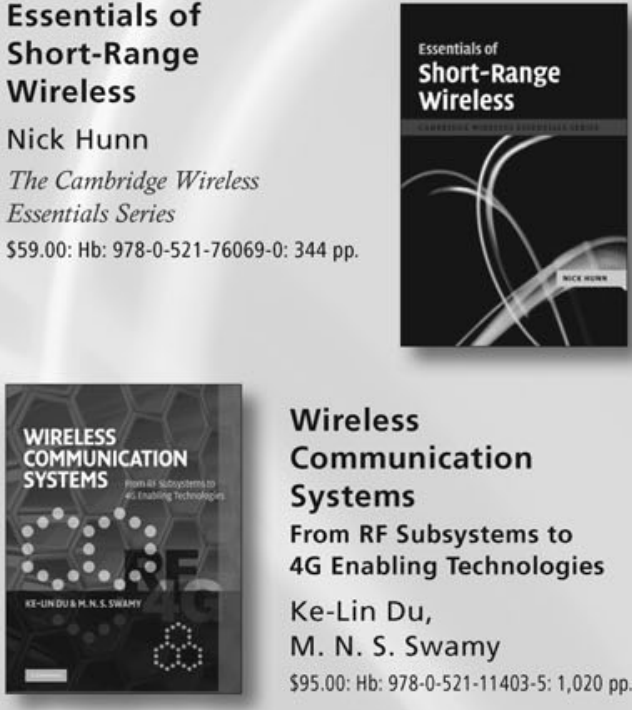

Wireless

Communication

Systems

From RF Subsystems to 4G Enabling Technologies

Ke-Lin Du,

M. N. S. Swamy

\$95.00: Hb: 978-0-521-11403-5: 1,020 pp.

\section{Remarkable}

Engineers

From Riquet to Shannon

Ioan James

\$85.00: Hb: 978-0-521-51621-1: $218 \mathrm{pp}$. S34.99: Pb: 978-0-521-73165-2
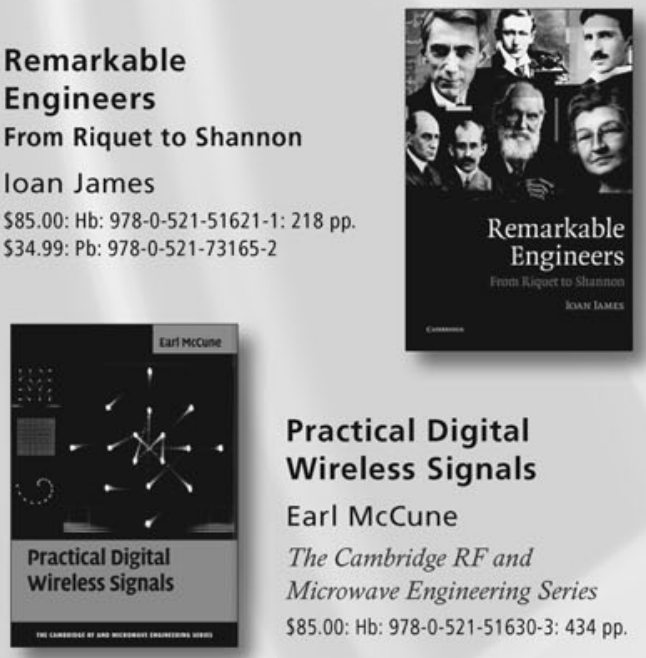

Practical Digital Wireless Signals

Earl McCune

The Cambridge RF and Microwave Engineering Series

585.00: Hb: 978-0-521-51630-3: $434 \mathrm{pp}$.

Second Edition

Radio-Frequency

Electronics

Circuits and Applications

Jon B. Hagen

\$80.00: Hb: 978-0-521-88974-2: 452 pp.

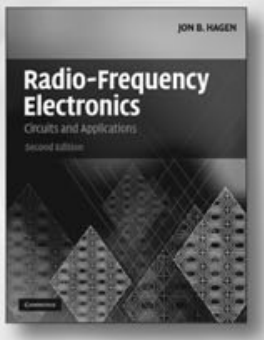

Prices subject to change.

www.cambridge.org/us/computerscience

800.872 .7423 


\section{Advertising Opportunities}

To advertise in this journal and for details of pricing, availability and discount opportunities please contact:

\section{Advertising in UK, Europe and rest of world}

The Advertising Sales Team

Cambridge University Press

The Edinburgh Building,

Shaftesbury Road,

Cambridge, UK, CB2 8RU

Tel: +44 (0)1223 325083

Email:ad_sales@cambridge.org

\section{Advertising in USA, Mexico and Canada}

Journals Advertising Coordinator

32 Avenue of the Americas,

New York,

NY 10013-2473, USA

Tel: +1 (212) 3375053 Fax: +1 (212 337 5959)

E-mail: journals_advertising@cambridge.org

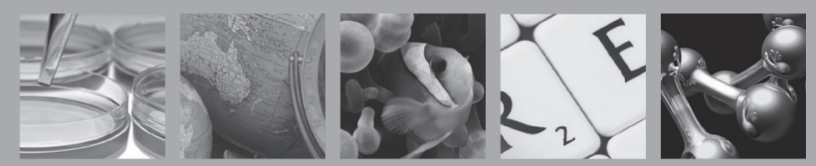




\section{INTERNATIONAL JOURNAL OF}

\section{MICROWAVE AND WIRELESS TECHNOLOGIES}

\section{CONTENTS}

Division by current: a new approach to FET capacitance modeling

Stephen Maas

Including orbital fluctuations in the noise spectrum of autonomous circuits

Fabio L. Traversa and Fabrizio Bonani

On the evaluation of the high-frequency load line in active devices

Antonio Raffo, Gustavo Avolio, Dominique M.M.-P. Schreurs, Sergio Di Falco, Valeria Vadalà,

Francesco Scappaviva, Giovanni Crupi,

Bart Nauwelaers and Giorgio Vannini

Semi-physical nonlinear circuit model with device/physical parameters for HEMTs Hiroshi Otsuka, Toshiyuki Oishi, Koji Yamanaka, Mattias Thorsell, Kristoffer Andersson, Akira Inoue, Yoshihito Hirano and Iltcho Angelov

ORIGINAL ARTICLES

Optimization criteria for power amplifiers

Jacques B. Sombrin

Highly efficient 3-stage Doherty power amplifier using gate bias adaption

Ildu Kim, Junghwan Moon, Jungjoon Kim,

Seunghoon Jee, Junghwan Son and Bumman Kim
A wideband CMOS distributed amplifier with slow-wave shielded transmission lines

Rosa R. Lahiji, Linda P.B. Katehi and

Saeed Mohammadi

Noise properties of balanced amplifier

configurations

E.E.M. Woestenburg

A dual wideband Sierpinski carpet fractal-shaped planar monopole antenna with CPW feed Rowdra Ghatak, Swapan K. Ghoshal,

Durbadal Mondal and Anup K. Bhattacharjee

Dosimetry of an in vitro exposure system for fluorescence measurements during 2.45 GHz microwave exposure

Mohamad Kenaan, Mihaela G. Moisescu, Tudor Savopol, Diana Martin, Delia Arnaud-Cormos and Philippe Leveque 